\title{
IDEAL ÉTICO DE HUMANIDADE: HUSSERL E SUAS LIÇÕES SOBRE FICHTE ${ }^{1}$
} Thiago Santoro (UFG) ${ }^{2}$ thsantoro@gmail.com

Resumo: $O$ presente trabalho pretende oferecer uma breve apresentação das preleções que Husserl dedica à filosofia de Fichte, mais especificamente à discussão sobre a relação entre ética e religião que os textos fichteanos desenvolvem em sua fase intermediária. O curso ministrado por Husserl, divido em três lições e apresentado na cátedra de Freiburg entre os anos 1917 e 1918, parece mostrar claramente a íntima conexão entre as propostas husserlianas acerca de uma fundamentação absoluta da ética e a teoria defendida por Fichte a respeito dos diferentes estágios ou graus de desenvolvimento moral da humanidade. Mais do que isso, ambas as posições filosóficas idealistas concebem estreita ligação entre a concepção de um ideal ético e a defesa de uma visão sobre a natureza humana que compreende a mesma como puro agir da consciência. Nesse sentido, o artigo almeja apresentar alguns pontos importantes da leitura husserliana de Fichte nesse ciclo de lições.

Palavras-chave: Husserl, Fichte, Ética, Religião.

\section{IDEAL ÉTICO DE HUMANIDADE: HUSSERL, LEITOR DE FICHTE}

Toda filosofia corre o risco do idealismo ${ }^{3}$. E todo idealismo corre, mais ainda, riscos diversos. Se limitamos o escopo da investigação filosófica ao campo epistêmico, o idealismo radical, na sua defesa de uma primazia da consciência ante o

\footnotetext{
${ }^{1}$ Recebido: 20-06-2016/ Aceito: 18-08-2016/ Publicado on-line: 28-08-2016.

${ }^{2}$ Thiago Suman Santoro é Professor Adjunto de Filosofia da Universidade Federal de Goiás, Goiânia, GO, Brasil.

${ }^{3}$ De fato, Fichte (1997) chega a afirmar que toda posição genuinamente filosófica é sempre um idealismo.
} 
dado material do objeto, no seu discurso em primeira pessoa que separa o eu de todo não-eu, ou mesmo na sua ênfase do ato construtivo frente a passividade do ser - esse idealismo radical, repito -, precisa com isso explicar como consegue afugentar os fantasmas da realidade como ficção, do solipsismo, bem como da ideia de uma ação pura sem objeto. Se consideramos a parcela ética da investigação filosófica idealista, corremos aqui o risco de elaborar um discurso excessivamente centrado no dever-ser, isto é, a tentativa de compreensão da natureza humana em seu modo de agir no mundo pode ceder lugar a um pétreo e dogmático ímpeto de reforma, seguido muitas vezes de mero moralismo caduco.

Por outro lado, todo idealismo pode ser visto como uma filosofia em potência, ainda não adequadamente bati$z a d a^{4}$. Há em todo idealizar uma dupla vertente, um duplo sentido que o termo grego idea inevitavelmente carrega: em primeiro lugar, nosso pensar sobre o mundo revela, por si mesmo, que o mundo só é pensável na própria linguagem do pensar, e aqui o uso das ideias, como meio de tradução do mundo, impõe de forma necessária sua marca - do ser ao não-ser, permanecemos enclausurados em nossos modos de apreensão. No segundo sentido, idea transforma-se em ideal, na medida em que lidamos com outro traço característico da natureza humana, e por que não dizer, talvez também de alguns primatas mais evoluídos: refiro-me à nossa capacidade de estabelecer finalidades, de criar metas e expectativas relativas a uma instância construída como mo-

\footnotetext{
${ }^{4} \mathrm{Ou}$, como afirma Husserl em seu Festschrift ao mestre Brentano, "Nos sistemas idealistas problemas e dimensões filosóficas completamente novas e radicais vem à luz, e apenas com o desenvolvimento do método filosófico que é requerido pelos insights desses sistemas é que os últimos e mais elevados fins da filosofia emergem." (Apud HART, 1995, 137).
} 
delo. Não só a cognição humana, senão também a ação humana no mundo encontram-se pautadas e conduzidas pelo conjunto de conceitos que determinam tais realizações. Todo idealismo parece revelar, mesmo que apenas nas entrelinhas, aquela síntese entre praxis e theoria tão corretamente captada pela doutrina platônica ${ }^{5}$ da verdade como sumo bem - e deixemos o terceiro termo da relação, o caráter estético dessa tríade, para ocasião outra.

Nesse sentido, tanto Husserl - se me permitem o risco da tese - como, de modo talvez mais convicto, Fichte apresentam-se sobretudo como filósofos idealistas. Não só, mas ambos autores compartilham de um idealismo pleno, ou seja, aquele que abarca filosofia prática e teórica em um único sistema, e ambos almejam, além disso, explicar de que forma tais ramificações vinculam-se internamente, de que modo idealismo ético e idealismo epistêmico determinam-se reciprocamente. Dito de outro modo, o sistema filosófico fichteano e, em certa medida, a filosofia de Husserl desenvolvida a partir da influência desse sistema pretendem apresentar o que poderia ser denominado, talvez de forma um tanto anacrônica, como visão de mundo, uma teoria que integra agir e saber, ou melhor, a compreensão do agir e a compreensão do saber, através de um mesmo princípio.

Tal como os célebres - infames, para alguns! ${ }^{6}$ - Discursos à

\footnotetext{
${ }^{5}$ Em vários pontos de seus cursos, Husserl compara positivamente Fichte a Platão.

${ }^{6}$ Essa alcunha negativa deve-se, sobretudo, ao uso deturpado que alguns teóricos adeptos do regime nazista fizeram de trechos isolados do texto fichteano, da mesma forma como o fizeram com Nietzsche, na tentativa de encontrar justificativas dentro da história do pensamento germânico para seu antissemitismo. O exemplo mais distorcido desse uso ideológico do texto fichteano encontra-se na obra de BERGMANN, 1933.
} 
Nação Alemã, proferidos por Fichte em plena invasão da Prússia por Napoleão, também as Lições sobre o Ideal Fichteano de Humanidade foram proferidas por Husserl, em seu primeiro ciclo, para soldados alemães recém chegados dos fronts da Primeira Guerra. ${ }^{7}$ Pouco me interessa aqui, no entanto, destacar os meandros político-sociais de uma situação tão triste e complexa, meandros que alimentaram os ânimos nacionalistas destes dois grandes filósofos, a ponto, muitas vezes, de provocar afirmações teuto-cêntricas descabidas $^{8}$. Quiçá, poderíamos especular, qualquer pensador em meio à crise da guerra teria dito o mesmo, teria reafirmado a autonomia de sua nação. Quiçá, também, todo grande pensador jamais esteja completamente isento de prejuízos pessoais e preconceitos datados de sua época e delimitados por seu círculo cultural.

Deixando, portanto, tais pormenores historiográficos de lado, pretendo mostrar, ainda que de forma bastante incipiente, de que forma as lições husserlianas em questão apontam certa confluência entre os dois filósofos em questão no que diz respeito ao estabelecimento de uma teoria ética normativa, e mais precisamente indicar em que medida a posição desenvolvida por Husserl é devedora da imensa influência exercida por sua leitura dos textos fichteanos. Tais lições podem esclarecer ainda como cada um dos autores considera a relação entre ética e religião, e se seria ou não possível compreender tal relação enquanto uma relação de fundamentação. A partir desses esclarecimentos será possivel, por fim, compreender melhor como Husserl desenvolve, sob a influência fichteana, uma teoria a respeito

\footnotetext{
${ }^{7}$ Cf. HART, 1995, 135.

${ }^{8}$ Para uma análise detalhada desse problema, cf. ABIZADEH, 2005.
} 
da natureza humana, e assim determinar qual o sentido preciso de um ideal ético de humanidade .

Algumas palavras introdutórias sobre a obra: essa última expressão - "ideal ético de humanidade" - corresponde a uma possível tradução do título do texto de Husserl sobre Fichte, texto divido em três lições e apresentado na cátedra de Freiburg entre os anos 1917 e 1918. Nessas palestras, a forma fidedigna com que Husserl reproduz diversas das teses centrais das obras populares tardias de Fichte bem como o tom bastante elogioso e entusiasmado ${ }^{9}$ com relação à própria persona filosófica desse verdadeiro luminar do Idealismo Alemão aparecem aqui em radical contraste à opinião crítica ou muitas vezes indiferente de Husserl, mantida em sua primeira fase, e certamente influenciada pelas críticas contundentes de Brentano. ${ }^{10}$ No entanto, como indica a pesquisa dos editores da obra do filósofo, desde seu período em Göttingen Husserl já iniciara leitura intensa dos escritos de Fichte, e proferiu por três semestre alternados (em 1903, 1915 e 1918) um curso sobre A Vocação ou Destinação da Humanidade, ${ }^{11}$ obra fichtiana publicada em 1800 .

Tomando em consideração as nefastas circunstâncias históricas, já acima esclarecidas, que permeiam esse ciclo de lições, Husserl inicia seu texto louvando os alicerces de uma moderna tradição intelectual e espiritual alemã que, segundo seu diagnóstico crítico, encontrava-se então em declínio. Não só os desenvolvimentos científicos cruciais de Copérnico e Kepler, a mente polímata de Leibniz, bem como as proezas literárias de Goethe ou Schiller, mas também Kant

\footnotetext{
${ }^{9}$ Como confirma sua carta de 1915 endereçada a Rickert (APUD HART, 1995, 136).

${ }^{10}$ Cf. BRENTANO, 1968, 23.

${ }^{11}$ Cf. HART, 1995, 135.
} 
e seus prosseguidores, Fichte, Schelling, Hegel, Schopenhauer, essa "cadeia suntuosa de montanhas com muitos picos dificilmente alcançáveis” (HUSSERL, 1987, p. 267) ${ }^{12}$, para utilizar a expressão do próprio autor, forjaram uma herança cultural que aparece agora ameaçada. E tal ameaça surge a partir de uma mudança radical de mentalidade ocorrida em meados do século XIX, uma completa inversão da visão transformadora proposta pelo Idealismo Alemão que tem em sua base o domínio onipresente das "ciências exatas" e de sua correspondente "cultura técnica" (sim, essa é uma afirmação de Husserl, o filósofo de formação matemática!). Eis o principal motivo, segundo o autor, para que essa tradição gigantesca, tanto em escopo quanto em profundidade, tenha provocado tamanho estranhamento em sua recepção póstuma, especialmente entre leitores do meio intelectual e acadêmico alemão na virada do século XX .

Assim, se Husserl tem como objetivo mais imediato nessas lições revigorar o espírito de seus compatriotas, isso de forma alguma reduz o significado mais universal presente nessa apresentação husserliana de Fichte ${ }^{13}$, a saber, trazer novamente à luz uma concepção sobre a natureza ética do indivíduo humano que ressalta sua nobreza interior e seu papel crucial na manifestação de um telos fundado na própria natureza divina. Não por acaso a vitória prussiana, posterior ao embate de Jena em 1806, só foi possível, de acordo com Husserl, "através do novo espírito que o Idealismo Alemão e seu porta-voz naquele tempo, Fichte, despertou naquele país." (1987, p. 268). E o despertar dessa

\footnotetext{
${ }^{12}$ Todas as traduções são minhas, tendo como apoio a tradução para o inglês de James G. Hart.

${ }^{13}$ Husserl descreve o filósofo idealista como um sujeito de espírito eminentemente prático, "reformador ético-religioso, educador, profeta e visionário." $(1987,269)$.
} 
força renovada é aqui descrito pelo autor como um "retornar interior a elevados ideais éticos e religiosos." (Ibidem) .

Justamente com esse objetivo maior em mente, Husserl, ao longo das três lições em questão, discorre sobre aquilo que Fichte denominou como "cinco estágios da vida" ou também como "cinco visões de mundo". No entanto, antes de esclarecer como cada uma dessas etapas é explicada pelos dois filósofos, e como podemos compreender de que modo essa quintuplicidade ética encontra-se fundada na própria teoria idealista a respeito da cognição humana ${ }^{14}$, vejamos como, a partir de uma breve análise da tese fichtiana fundamental acerca da noção de subjetividade, Husserl aponta nessa direção .

\section{II}

"A filosofia trata de questões cujo conteúdo não pode ser objeto de indiferença para ninguém, pois tomar uma posição com relação a elas é decisivo para a dignidade da genuína humanidade.” (HUSSERL, 1987, 270). Essa formulação emblemática de Husserl bem ilustra uma aspecto crucial da concepção filosófica de Fichte, que se estende tanto ao fundamento teórico de seu sistema quanto à aplicação ou ao desdobramento prático da doutrina-da-ciência. Abdicar da explicação sobre sujeito e mundo proveniente da posição ou postura natural em direção ao idealismo só é possível, mesmo no sentido estritamente teórico, através de uma escolha fundamental ${ }^{15}$, através de uma decisão profunda a

\footnotetext{
${ }^{14}$ Como afirma Husserl $(1987,270)$, "todas essas intuições ético-religiosas são ancoradas na teoria." Teoria refere-se aqui à Doutrina-da-Ciência.

${ }^{15}$ Essa tese sui generis da filosofia fichtiana apresenta-se de forma mais emblemática na Primeira Introdução à Doutrina-da-Ciência, §5. Cf. FICHTE, 1997, 14-20.
} 
respeito do modo como compreendemos nossa própria natureza no mundo. Caso queiramos preservar a ideia de liberdade do espírito finito, e com isso fundamentar algum sentido de finalidade em nosso agir, faz-se necessário adotar em termos cognitivos a inversão explicativa que o idealismo acarreta .

Por outro lado, como fica bastante explícito com a reconstrução que Husserl apresenta nesse texto das origens modernas do idealismo, através das teses de Descartes e Kant, há na virada transcendental a percepção de um limite intransponível para toda investigação. A determinação de um caminho de mão única que parte sempre dos princípios imanentes à razão, ou, para adotar um vocabulário mais próximo à fenomenologia, a doação de sentido a qualquer conteúdo noemático, só alcança o mundo através dessa construção ou constituição imanente à consciência. Como afirma Husserl,

assim, nesse idealismo realiza-se uma paradóxica inversão do modo natural naïve de pensar. Mas que monstruosa imposição no "sadio" senso comum! A subjetividade é mundo-creativa, formando o mundo a partir de materiais pré-dados da sensação de acordo com leis rígidas $(1987,273)$.

Só assim podemos melhor compreender também o elogio husserliano à revolução ou radicalização do kantismo inaugurada por Fichte, ao afirmar que esse "tipo completamente novo de interpretação de mundo" se coloca "em contraposição à interpretação natural do mundo de forma nova e dificilmente superável." (1987, 276). Husserl se refere aqui mais precisamente à tese fichtiana a respeito do puro estado-de-ação do eu, expressão inclusive que intitula a primeira 
lição do texto. ${ }^{16}$ Ao reproduzir uma distinção fundamental da doutrina-da-ciência, a saber, aquela entre Tathandlung e Tatsache, o autor confirma a inadequação de qualquer hipótese a respeito de uma coisa-em-si transcendente à razão ${ }^{17}$, e assim reinterpreta os conceitos de sujeito e objeto sob a ótica do idealismo transcendental. Como esclarece Husserl (1987, 275), "portanto, não só é congruente ser um sujeito e ser algo que age; mas também ser um objeto para um sujeito e ser um produto do agir."

Ao final dessa primeira lição encontramos uma cadeia argumentativa, talvez excessivamente resumida, que estabelece de forma mais precisa o vínculo entre os aspectos epistêmicos e éticos da noção idealista de subjetividade. Primeiramente, Husserl entende a construção da noção de subjetividade a partir dessa ação pura como a história subjetiva formada pelo conjunto de ações realizadas pelo sujeito, de sorte que podemos assim falar de um desenvolvimento ou de um progresso que concatena tais ações. $\mathrm{O}$ segundo passo da argumentação mostra que essa sequência de ações, cada qual superando a anterior, progride ao infinito ${ }^{18}$, e, justamente porque toda ação é sempre dirigida a um fim, cada passo superado exige o postular de um novo passo, cada etapa desse desenvolvimento da ação subjetiva gera ou produz uma nova finalidade. Mas se isso é valido para o sujeito, então precisamos também considerar - e aqui temos a

\footnotetext{
${ }^{16}$ O subtítulo no original é "Das absolute Ich der Tathandlungen".

17 "Através da eliminação das coisas-em-si é eliminada a afecção. Agora permanece na subjetividade enquanto resíduo morto um emaranhado de materiais das impressões sensíveis. Pode haver na subjetividade algo que não tenha sido produzido por ela? Não. O sujeito é por completo e nada mais do que aquilo que age. E o que quer que o sujeito tenha diante de si, enquanto subtrato da ação, enquanto objeto de sua atividade, deve ser algo imanente a ele" (HUSSERL, 1987, 274 75).ething alreay enacted

${ }^{18}$ Eis o Leitmotiv fichteano que tanto encantou seus adeptos no Romantismo Alemão.
} 
terceira parte do argumento -, que existe uma unidade teleológica do conjunto dessas ações, que existe um nexo subjetivo apontando para o que Husserl, seguindo de perto as formulações fichtianas, denomina "mais elevada finalidade moral." (1987, 275) .

Vemos assim de que modo existe um duplo sentido para o idealismo desses autores, ou dito de outra maneira, uma determinação por bi-implicação entre os idealismos ético e epistêmico defendidos por ambos os filósofos. Resta esclarecer ainda quais os desdobramentos específicos dessa posição na teoria ética propugnada por Fichte, especialmente aquela apresentada na obra tardia Exortação à Vida Bemaventurada $^{19}$, tal como esta se encontra reconstruída por Husserl nas duas outras lições desse ciclo. O próprio Husserl assume, em carta a seu amigo Grimme ${ }^{20}$, uma estreita proximidade entre o ponto de vista religioso aberto pela fenomenologia e aquele desenvolvido pela obra fichtiana.

\section{III}

O primeiro grau de desenvolvimento moral da humanidade - e aqui cabe também designá-lo por primeira etapa do desenvolvimento espiritual do indivíduo - é um estágio bem conhecido por todos. De fato, poderíamos conjecturar que talvez a maior parte da humanidade vivente, hoje mais do que nunca, encontra-se ainda enredada nesse ponto. Tratase neste caso, conforme a reconstrução husserliana das teses de Fichte, daquela visão de mundo que "atribui a realidade

\footnotetext{
${ }^{19}$ Sem dúvida há aqui uma convergência entre a exposição fichtiana dos graus de desenvolvimento moral da humanidade apresentada na referida obra e aquela que Fichte desenvolve, durante o mesmo ano, no texto intitulado Die Grundzüge des gegenwärtigen Zeitalters, também de 1806.

${ }^{20}$ Cf. HART 1995, 142.
} 
ao mundo sensível ou à natureza."21 Mais do que isso, lidamos aqui com a postura ética intimamente vinculada a tal visão de mundo, a saber, aquela que direciona toda finalidade da ação humana à satisfação imediata dos sentidos. Mesmo que isso não conduza necessariamente todo e qualquer agente ao puro e extremo hedonismo, importa observar que o princípio norteador dessa postura apresenta uma finalidade sempre heterônoma, e por isso mesmo uma contínua insuficiência no cumprimento dessa mesma finalidade. A controvertida expressão husserliana não poderia ser aqui mais acertada:

No esgotar-se do efêmero mundo dos sentidos e da aparência não há, como já vimos, qualquer satisfação. Caso nada mais existisse, então o túmulo seria a única salvação. Mas como alguém atinge a beatitude deixando-se ser sepultado? (HUSSERL, 1987, 285).

Assim, em contraste radical com o estágio de desenvolvimento moral anterior, surge um primeiro passo para a profunda transformação da visão de mundo do ponto de vista natural. Com o modelo paradigmático da ética kantiana chegamos à teoria de uma moralidade autônoma, na medida em que a ação do sujeito deve agora pautar-se por um princípio intrínseco à própria razão pura, e consequentemente o estabelecimento de fins para esse agir é também, de acordo com a tese kantiana, uma finalidade em si mesma. Nesse sentido o imperativo moral, ao introjetar na própria consciência a finalidade da ação, já realiza uma espécie de libertação, e permite um primeiro vislumbre da teleologia intrínseca ao sujeito humano .

No entanto, essa obediência irrestrita e formal às má-

\footnotetext{
${ }^{21}$ Cf. Die Anweisung zum seligen Leben. FICHTE, 2001, 77.
} 
ximas morais da razão, essa ética formalista que Husserl, seguindo a posição do Fichte tardio, qualifica criticamente como estoica, parece produzir justamente através de seu formalismo um segundo aprisionamento, uma segunda limitação ao pleno desenvolvimento moral. Husserl observa que essa postura estoica se mantém condicionada por aquilo que ela nega, e nesse sentido apresenta-se como pura negatividade. Ao seguir de forma rígida a lei moral, e ao negar toda e qualquer motivação proveniente da sensibilidade, o modelo proposto pela ética kantiana acaba esvaziando-se de "valores positivos absolutos", e assim, conforme esclarece Husserl, determina de fato uma liberdade também vazia. Eis a forma como o autor apresenta esse ponto: "essa liberdade da apatia estóica é ainda uma liberdade vazia. $\bigcirc$ amor que move o estoico dispensa toda positividade. Ele é um amor apenas formal à liberdade. Portanto, falta-lhe conteúdo." (HUSSERL, 1987, 286).

É justamente através dessa crítica ao formalismo moral kantiano que a teoria fichtiana exposta por Husserl pode então, numa notável antecipação com termos invertidos da Filosofia do Direito hegeliana, estabelecer uma distinção crucial entre a mera eticidade (Sittlichkeit) e uma moralidade própria e elevada (Moralität). Surge assim a designação da terceira etapa do progresso moral humano. Nessa etapa, o agir individual é regido também por um princípio autônomo, por uma autodeterminação. Contudo, há aqui uma autonomia acompanhada de entusiasmo, uma determinação de si movida pelo amor incondicional ao conjunto de ideias ou valores absolutos. Temos nessa perspectiva uma ação abnegada, pois, ao contrário do orgulho centrado em si do moralismo estoico, o sujeito que atingiu a moralidade elevada atua apenas em função da realização da própria ideia. 
Por isso não lidamos mais com um esforço restritivo, com uma proibição do sensível, senão que com a realização daquilo que Fichte denomina "vocação", expressão legítima para todo indivíduo que, guiado pelo amor à ideia, consagra seu agir no mundo, seu Lebenstrieb. Husserl exemplifica essa etapa moral através da produção do artista, afirmando o seguinte: "na consciência criativa do artista, na pura espontaneidade com que o conceito do artista se realiza, revela-se a divindade, e ela se revela sob a forma dessa ideia." $(1987,288)$.

A passagem do terceiro ao quarto nível de desenvolvimento moral é uma passagem sutil. Mesmo com a consagração do agir individual à obra enquanto tal, enquanto realização da ideia no mundo, falta ainda ao sujeito ou agente plena consciência da verdadeira finalidade dessa mesma ação. Como explica Husserl, ao delimitar a quarta postura denominada por Fichte de estágio ou visão de mundo da religião:

De qualquer modo, se o indivíduo examinar a si mesmo, ele perceberá que não é a obra exterior que tem um valor absoluto e que é um fim em si mesmo, mas exclusivamente a pessoa ela mesma enquanto aquela que deseja e cria a obra! E, finalmente, ele poderá ter clareza de que aquilo que ele realmente desejou e para o qual esforçou-se é o desdobramento do ser e da vida divinos em seu próprio ser e esforço. (HUSSERL, 1987, 290).

Assim, o ponto de vista religioso parece estabelecer agora, por via da ação abnegada do estágio anterior, um estatuto especial à natureza espiritual humana, na medida em que direciona a realização do telos não mais ao produto da ação, mas sim ao próprio agir. Em certo sentido, há aqui uma interiorização teleológica mais profunda, condizente com a tarefa transformadora que o idealismo transcendental, em 
sua acepção mais radical, pretende realizar. A via única de acesso cognitivo ao mundo a partir do sujeito revela, destarte, um sentido próprio também para o ethos decorrente dessa posição. Husserl não deixa dúvidas sobre isso na seguinte passagem do texto:

Aquele que escalou até esse elevado ponto vê o mundo com novos olhos. E isso é especialmente verdadeiro sobre o mundo social humano. Esse sujeito percebe que Deus vive em cada ser humano a partir de uma forma única, mesmo quando oculto por algum invólucro. $(1987,290-1)$.

Qual é então o limite para essa ascensão moral, de acordo com a proposta fichtiana analisada por Husserl? Se a perspectiva religiosa produz uma interiorização desse fato a respeito de uma possível ligação entre o absoluto e sua manifestação finita, é apenas a partir do ponto de vista da ciência ou filosofia que tal ligação é propriamente compreendida. Vemos aqui de que modo tanto Husserl quanto Fichte conduzem a argumentação transcendental sobre o fundamento ideal da ética, pois em ambos os casos encontramos uma ligação entre o Absoluto e sua imagem compreendida a partir de uma análise do limite interno ao saber. Hart, em sua apresentação do texto husserliano, aponta diretamente ao problema com a seguinte explicação sobre o ponto de vista da doutrina da ciência:

Para Fichte a filosofia ocorre dentro do âmbito do Wissen [saber] que é o da [aí] ou Bild [imagem] de Deus. E também Fichte assume um absoluto fora desse primeiro absoluto do âmbito próprio à filosofia, i.e., Wissen [saber]. Deus ele próprio enquanto puro e absoluto Sein [ser] é o princípio da Luz e do Wissen [saber] e, portanto, completamente transcendente à filosofia. $(1995,156)$.

E dita compreensão se dá por aquilo que Husserl de- 
nomina uma "intuição filosófica consumada" 22 , isto é, a partir da explicação sistemática da relação entre a consciência individual e o próprio Absoluto, explicação esta que parte sempre de uma análise dos modos imanentes à própria consciência enquanto manifestação. No entanto, tal análise do fenômeno cognitivo subjetivo, isso que talvez nos permita entrar em contato intuitivo com a própria essência constitutiva de nossa consciência, funciona sempre como um recurso indireto, deve sempre apontar para fora de si, ou melhor, indicar por via negativa aquilo que permanece para além do binômio sujeito-objeto que toda atividade intencional da consciência necessariamente produz. Como bem esclarece a seguinte passagem do comentário de Hart,

Se o Dasein [ser-aí], como o da [aí] ou Bild [imagem] do Sein [ser], deve encontrar um caminho ao Sein [ser], ele necessita contornar seu saber objetificante. Ele deve superar a relação sujeito-objeto que, para Fichte, está em jogo em toda categorização, linguagem, atividade conceitual e sintática. De algum modo ele deve abstrair deste tipo de intencionalidade e recuperar aquilo que é prévio ao seu devir, sua gênese. $(1995,159){ }^{23}$

Nesse sentido, a análise imanente dos modos de constituição do sujeito aplicada à ética poderia, mesmo sem estabelecer uma prova cabal, ao menos indicar por via indireta não só a natureza singular e ao mesmo não conceitualizável da consciência pura, mas também se devemos ou não pressupor, como fundamento de sentido da ação regida por fins, isto é, como fundamento da própria concepção idealista da ética, uma inteligência absoluta como princípio ordenador. Teríamos com isto certa correspondência entre o

\footnotetext{
${ }^{22}$ A expressão original é “vollendeter philosophischer Einsicht.” Cf. HUSSERL, 1987, 291.

${ }^{23} \mathrm{Ou}$, como sugere Husserl, "através disso a fé simples eleva-se, mediante o conhecimento filosófico, a um Ver (Schauen).” (1987, 292).
} 
caminho fenomenológico de investigação da essência da consciência pura individual e o procedimento fenomenológico que pretende estabelecer um ideal ético da humanidade através do conceito de divindade:

Mas porque nós humanos cognoscentes somos eus, nos quais esse eu absoluto dividiu a si mesmo, podemos, através de uma imersão intuitiva naquilo que pertence à pura essência do eu ou da subjetividade, reconstruir os necessários processos teleológicos a partir dos quais o mundo, incluindo a nós mesmos (naquilo que para nós é um imperar inconsciente da absoluta inteligência) foi formado, e formado em necessidade teleológica. (HUSSERL, 1987, 276 - grifo meu).

E logo na sequência do texto, Husserl complementa essa tese, indicando claramente como esta investigação conjunta de fato estabelece a verdadeira e mais nobre tarefa legada à atividade filosófica, a saber, aquela que ao retroceder do fenômeno material mais bruto retorno à natureza interna da consciência em busca de um sentido último, ou absoluto, para fundamentar essa mesma consciência ${ }^{24}$. Eis, portanto, o vínculo íntimo entre o processo epistêmico de colocar o mundo entre parêntesis, para assim revelar o conjunto de essências ideais imanentes à vida consciente, ou conjunto de ações constitutivas da consciência, e a investigação sobre uma instância superior que serve de fundamento àquele conjunto de ações, agora não mais restritas à esfera epistêmica, mas abarcando sobretudo a totalidade de nossas ações no mundo, o que significa dizer que esse fun-

\footnotetext{
24 "A fenomenologia sente-se chamada a responder a uma interrogação ética. A ideia de justificação última e a necessidade de uma tomada de consciência vão de par com a necessidade de uma responsabilidade que tem como meta determinar a essência da práxis filosófica. Enquanto ciência universal, a filosofia é chamada a indicar a fonte originária de onde toda ciência traz a própria justificação última; ela não pode, assim, reduzir-se a um compromisso teórico. A vida de pensamento deve ser intensa, vivida na absoluta responsabilidade. Por conseguinte, a reflexão de Husserl sobre a ética não é um simples apêndice de seus trabalhos teóricos, e sim aquilo que esclarece e dá sentido a esses trabalhos." (FABRI, 2006, 74).
} 
damento último determina por sua vez um telos originário, um ideal ético de humanidade .

Se assim o fazemos, somos filósofos. E a única tarefa genuína da filosofia encontra-se aqui. Ela consiste em compreender o mundo como um produto teleológico do eu absoluto e, na elucidação da criação do mundo no absoluto, tornar evidente seu sentido último. (HUSSERL, Ibidem).

Abstract: This paper aims to provide a brief presentation of Husserl's lectures dedicated to the philosophy of Fichte, specifically the discussion of the relationship between ethics and religion that the fichtian texts develop in its intermediate phase. The course taught by Husserl, divided into three lessons and presented in the chair of Freiburg between the years 1917 and 1918, seems to clearly show the intimate connection between Husserl proposals on an absolute foundation of ethics and the theory advocated by Fichte about the different stages or degrees of moral development of mankind. More than that, both idealistic philosophical positions conceive a close relation between the conception of an ethical ideal and the defense of a view about human nature that understands it as a pure acting of consciousness. In this regard, the paper aims to present some important aspects of Husserl's reading of Fichte in these cycle of lectures.

Keywords: Husserl, Fichte, Ethics, Religion.

\section{REFERÊNCIAS}

ABIZADEH, A. Was Fichte an Ethnic Nationalist? On Cultural Nationalism and its Double. Em: History of Political Thought. Vol. XXVI. No. 2, pp. 334-359, Summer 2005.

BRENTANO, F. Die vier Phasen der Philosophie. Hamburg: Meiner, 1968.

FABRI, M. A Atualidade da Ética Husserliana. Veritas, Porto Alegre, v. 51, n. 2, pp. 69-78, Junho, 2006.

FICHTE, J. G. Die Anweisung zum seligen Leben. Hamburg: Meiner, 2001. 
. Introducciones a la Doctrina de la Ciencia. Madrid: Tecnos, 1997.

HUSSERL, E. Aufsätze und Vorträge (1911-1921). Husserliana XXV. Hague: Martinus Nijhoff, 1987.

. Fichte's ideal of humanity. Three Lectures. Tradutor: James G. Hart. Em: Husserl Studies 12: 111-133, 1995.

HART, J. G. Husserl and Fichte: With special regard to Husserl's lectures on "Fichte's ideal of humanity". Em: Husserl Studies 12: 135-163, 1995. 